\title{
Ginsenoside Rg3 induces apoptosis in the U87MG human glioblastoma cell line through the MEK signaling pathway and reactive oxygen species
}

\author{
YOON JI CHOI ${ }^{1 *}$, HYUN JOO LEE ${ }^{2 *}$, DONG WAN KANG ${ }^{1}$, IN HO HAN ${ }^{1,2}$, \\ BYUNG KWAN CHOI ${ }^{1,2}$ and WON HO $\mathrm{CHO}^{1,2}$ \\ ${ }^{1}$ Department of Neurosurgery and Medical Research Institute, Pusan National University Hospital; \\ ${ }^{2}$ Pusan National University School of Medicine, Busan 602-739, Republic of Korea
}

Received March 15, 2013; Accepted May 2, 2013

DOI: $10.3892 /$ or.2013.2555

\begin{abstract}
Ginsenoside is known to have potential cancerpreventive activities. The major active components in red ginseng consist of a variety of ginsenosides including $\operatorname{Rg} 3, \operatorname{Rg} 5$ and $\mathrm{Rk} 1$, each of which has different pharmacological activities. Among these, $\mathrm{Rg} 3$ has been reported to exert anticancer activities through inhibition of angiogenesis and cell proliferation. However, the effects of $\mathrm{Rg} 3$ and its molecular mechanism on glioblastoma multiforme (GBM) remain unclear. Therefore, it is essential to develop a greater understanding of this novel compound. In the present study, we investigated the effects of $\mathrm{Rg} 3$ on a human glioblastoma cell line and its molecular signaling mechanism. The mechanisms of apoptosis by ginsenoside $\mathrm{Rg} 3$ were related with the MEK signaling pathway and reactive oxygen species. Our data suggest that ginsenoside $\mathrm{Rg} 3$ is a novel agent for the chemotherapy of GBM.
\end{abstract}

\section{Introduction}

In recent years, the discovery of new therapeutic reagents for cancer treatment has been studied in several countries. One of the most aggressive and malignant types of human cancer, glioblastoma multiforme (GBM), is a common brain tumor in humans $(1,2)$. The prognosis of GBM after diagnosis remains dismal, even after aggressive treatment such as radiotherapy, chemotherapy and surgery (3-5). Thus, it is necessary to identify new treatment modalities for GBM to achieve more favorable results.

Correspondence to: Dr Won Ho Cho, Department of Neurosurgery, Pusan National University Hospital, 305 Gedeok-Ro, Seo-Gu, Busan 602-739, Republic of Korea

E-mail:mdcwh@naver.com

${ }^{*}$ Contributed equally

Key words: ginsenoside Rg3, apoptosis, U87MG cell, MEK signaling, reactive oxygen species
Korean red ginseng (KRG; Panax ginseng C.A. Meyer), which is also generally known as Korean ginseng, is a native herbal remedy commonly used in Korea and China (6,7). Red ginseng has been recognized as a life prolonging herb in Asia for thousands of years (8-10). The major active components in red ginseng are the ginsenosides $\operatorname{Rg} 3, \operatorname{Rg} 5$ and $\mathrm{Rk} 1$, each of which has unique pharmacological activities $(11,12)$.

Ginsenosides have been reported to exert cancer-preventive effects against various types of cancer, such as lung cancer (13), nasopharyngeal carcinoma (14) and prostate cancer (15). Various components of ginsenosides are expected to exert a similar preventive effect against various types of cancer, but their effects against GBM remain unknown. In the present study, we investigated the effects of individual ginsenosides, particularly those of $\mathrm{Rg} 3$, on the human glioblastoma cell line, U87MG, and their molecular signaling mechanism.

\section{Materials and methods}

Reagents. $\mathrm{Rg} 3$ was purchased from NPC BioTech (Korea). DAPI stain, 3-(4,5-dimethylthiazol-2-yl)-2,5-diphenyltetrazolium bromide (MTT) and modified Hanks' balanced salt solution (HBSS) were obtained from Sigma-Aldrich (USA). $\alpha$-minimum essential medium (MEM) and fetal bovine serum (FBS) were acquired from Invitrogen (Canada). U0126, PD98059, SP600125, SB203580 and Z-VAD-fmk were obtained from Calbiochem (Denmark). An enhanced chemiluminescence (ECL) kit was purchased from Amersham Biosciences (UK). Bcl-2, Bax and pro-caspase 3 were acquired from Epitomics (USA). p-ERK, p-p38 and p-JNK were obtained from Cell Signaling Technology, Inc. (USA).

Cell culture conditions. U87MG cells (human glioblastoma cell line) were purchased from the Korean Cell Line Bank and cultured in $\alpha$-MEM supplemented with $10 \%$ heat-inactivated FBS, $100 \mathrm{U} / \mathrm{ml}$ penicillin and $100 \mu \mathrm{g} / \mathrm{ml}$ streptomycin. The cells were plated in cell culture dishes and cultivated at $37^{\circ} \mathrm{C}$ in a humidified $5 \% \mathrm{CO}_{2}$ incubator. These cells were then subcultured until confluence for 3-5 days using 0.05\% trypsin. Cells were cultivated under serum starved conditions for 1-2 days before various reagents were added. 

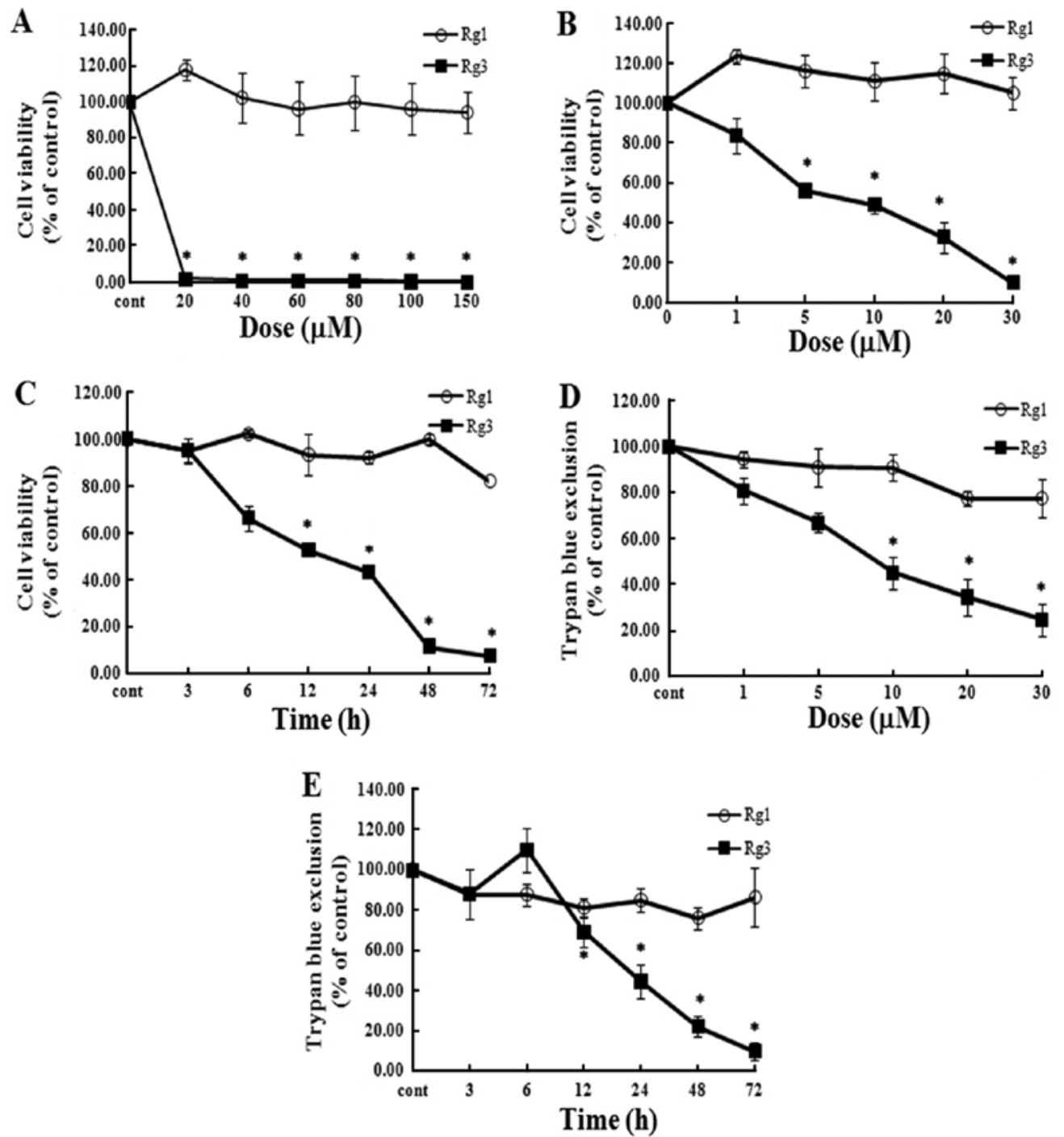

Figure 1. Viability of U87MG cells decreases in response to treatment with $\mathrm{Rg} 3$. Changes in viability in response to treatment with various concentrations of $\mathrm{Rg} 3$ or $\mathrm{Rg} 1$ for different time periods were measured using an MTT assay (A-C) and trypan blue exclusion assay (D and E). The cells were treated with $10 \mu \mathrm{M} \operatorname{Rg} 1$ and $\operatorname{Rg} 3$ (C and E). The data reported are the means \pm SEM of four independent experiments. ${ }^{~} \mathrm{P}<0.05$ when compared to the control without Rg3.

\section{Measurement of cell growth}

MTT assay. U87MG cells were seeded in 96-well plates at $5 \times 10^{2}$ cells/well with various concentrations of $\mathrm{Rg} 3$ for the indicated time periods. Following cultivation under various conditions, $0.5 \mathrm{mg} \mathrm{MTT} / \mathrm{ml}$ in $\alpha$-MEM was added. The cells were then cultivated for $2 \mathrm{~h}$, after which they were dissolved in DMSO and the absorbance of each well was measured at $570 \mathrm{~nm}$ using a 680 microplate ELISA reader (UK).

Measurement of cell death by a trypan blue dye exclusion assay. Rg3-treated cells were harvested using $0.05 \%$ trypsin solution and washed with HBSS buffer, after which they were suspended in $0.4 \%$ trypan blue solution. Cells that excluded the dye were considered viable. The cells were counted using a hemocytometer under light microscopy.

Flow cytometry. Cells were plated in 6-well plates at $5 \times 10^{4}$ cells/well, after which they were treated with the indicated reagents for $24 \mathrm{~h}$ at $37^{\circ} \mathrm{C}$. The cells were then harvested using $0.05 \%$ trypsin solution and centrifuged at $10,000 \mathrm{x}$ g for 15 min, after which the pellets were washed in HBSS buffer twice and fixing solution was added. The samples were then incubated overnight at $4^{\circ} \mathrm{C}$, stained with $50 \mu \mathrm{g}$ propidium iodide/ml containing $100 \mu \mathrm{g}$ R Nase/ml for $20 \mathrm{~min}$ and analyzed using a FACSort Becton-Dickinson Flow Cytometer (USA).

Staining of the apoptotic cells. DNA fragmentation was evaluated by terminal deoxynucleotidyl transferase (TdT)-mediated deoxyuridine triphosphate (dUTP) nick end labeling (TUNEL) assay using an in situ Cell Death Detection kit (fluorescein) purchased from Roche Applied Science (USA). Briefly, cells were plated at a density of $5 \times 10^{4}$ cells/cover slip $(25 \mathrm{~mm}$ size), and then treated with $\operatorname{Rg} 3$. The cells were subsequently washed, after which freshly prepared $4 \%$ paraformaldehyde was added and they were incubated for $60 \mathrm{~min}$ at $37^{\circ} \mathrm{C}$. Next, the samples were permeabilized in permeabilization solution ( $0.1 \%$ Triton X-100 in $0.1 \%$ sodium citrate) for $5 \mathrm{~min}$ on ice, then subjected to the TUNEL reaction at $37^{\circ} \mathrm{C}$ in a humidified atmosphere in the dark for $60 \mathrm{~min}$. Finally, the fluorescent signal was detected using a Zeiss fluorescence microscope (Germany).

Immunocytochemistry. Cells were plated at $5 \times 10^{4}$ cells/well cover slip (25 mm size), fixed in freshly prepared $4 \%$ para- 

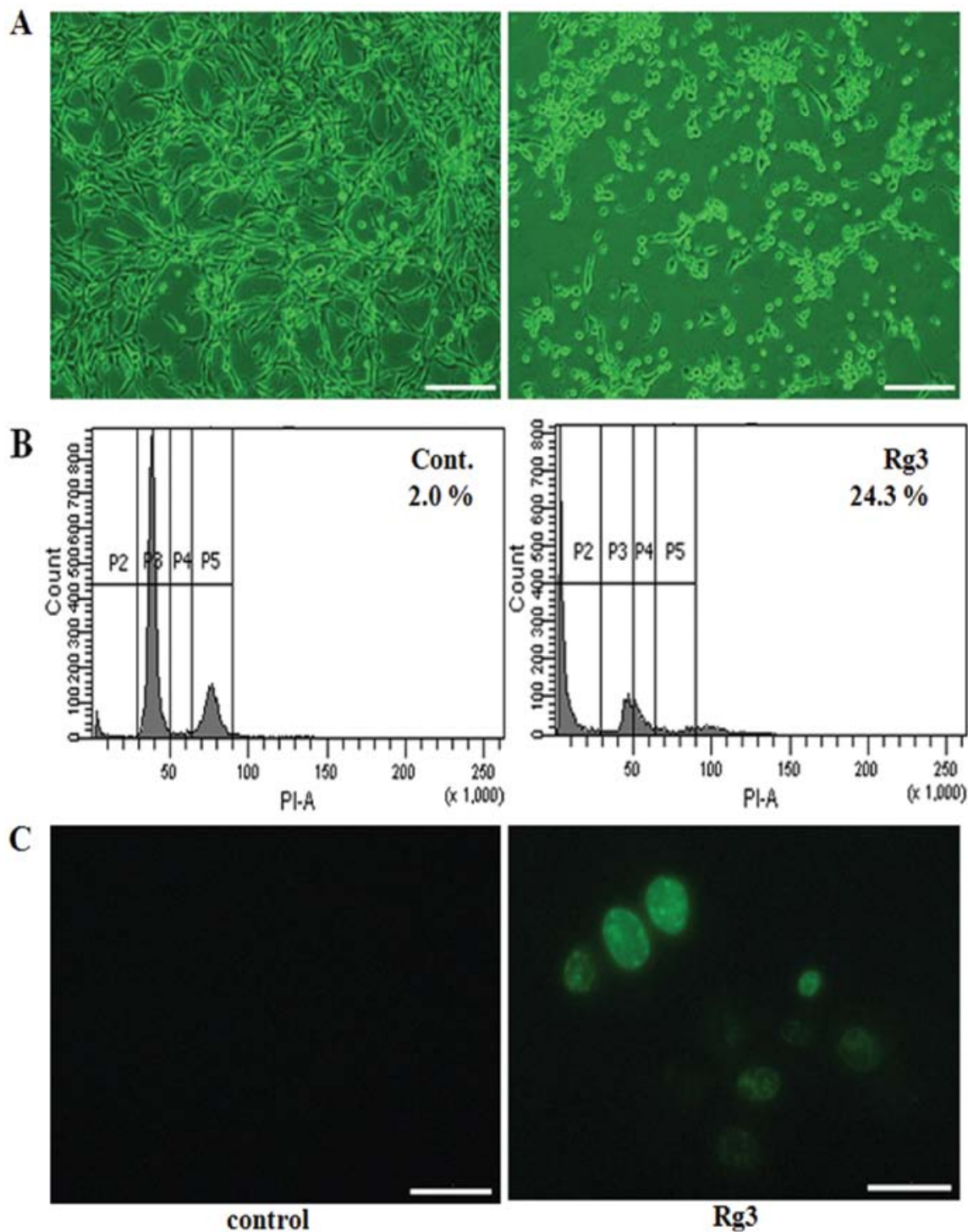

Figure 2. Rg3 induces apoptosis in U87MG cells. The cells showed clear morphological changes after $24 \mathrm{~h}$ of treatment with $10 \mu \mathrm{M} \mathrm{Rg} 3$ (A). The cells were treated with $10 \mu \mathrm{M} \mathrm{Rg} 3$ for $24 \mathrm{~h}$ and were examined by flow cytometric analysis (B) and TUNEL assay (C). The scale bar is $400 \mu \mathrm{m}$.

formaldehyde for $5 \mathrm{~min}$ and then washed. The cells were then blocked in $1 \%$ BSA blocking reagent for 30 min at room temperature, after which they were stained with primary antibodies such as Bax (1:500) and Bcl-2 (1:500) overnight at $4^{\circ} \mathrm{C}$ and washed. Next, secondary antibody was added and the cells were incubated for $2 \mathrm{~h}$, at which time they were subjected to DAPI staining. Fluorescent signals were detected using a Zeiss fluorescence microscope.

Western blot analysis. The cells were plated in 6-well plates at $5 \times 10^{4}$ cells $/ \mathrm{cm}^{2}$ and then lysed on ice using lysis buffer ( $\mathrm{pH} 7.4$; 1 mM EGTA; 1 mM EDTA; 0.1 mM phenylmethylsulfonyl fluoride; $10 \mathrm{mM} \mathrm{NaCl} ; 20 \mathrm{mM}$ Tris- $\mathrm{HCl} ; 1 \%$ Triton X-100). The lysates were then centrifuged at $10,000 \mathrm{x} \mathrm{g}$ for $20 \mathrm{~min}$ at $4^{\circ} \mathrm{C}$ and loaded onto a $15 \%$ sodium dodecyl sulfate-polyacrylamide gel electrophoresis (SDS-PAGE) gel, then transferred to nitrocellulose membranes. Membranes were immunoblotted with primary antibodies such as Bax (1:500), Bcl-2 (1:500) and $\beta$-tubulin $(1: 1,000)$. The membrane signals were visualized using an ECL kit.
Measurement of reactive oxygen species (ROS). The intracellular generation of ROS was detected using 2',7'-dichlorofluorescin diacetate (DCFH-DA). Briefly, cells were plated in 6-well plates at $5 \times 10^{4}$ cells $/ \mathrm{cm}^{2}$, pre-treated with antioxidant enzymes and then treated with Rg3. Following treatment, the cells were washed using PBS and incubated with $30 \mu \mathrm{M}$ DCFH-DA for $1 \mathrm{~h}$ at $37^{\circ} \mathrm{C}$, after which they were quickly washed, and the fluorescence signal intensity was monitored using a Zeiss fluorescence microscope.

Statistical analysis. All experiments were performed at least three times and statistical significance was determined using a Student's t-test (two-tailed). A P-value of $<0.05$ was considered to indicate a statistically significant difference.

\section{Results}

Rg3 exerts an inhibitory effect against U87MG cells. To test whether ginseng components exert inhibitory effects against U87MG cells, we conducted an MTT and a trypan blue assay. 

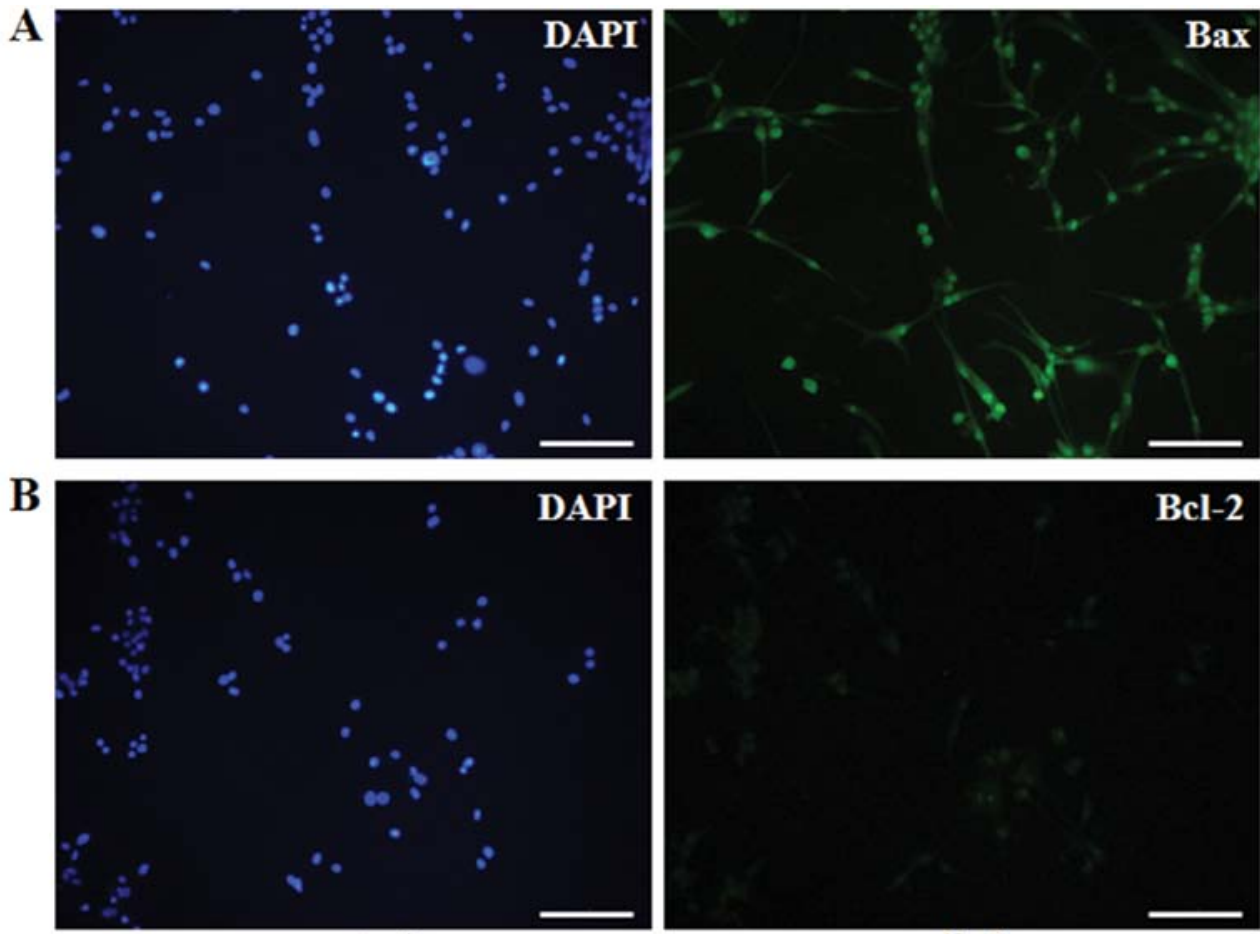

control

Rg3
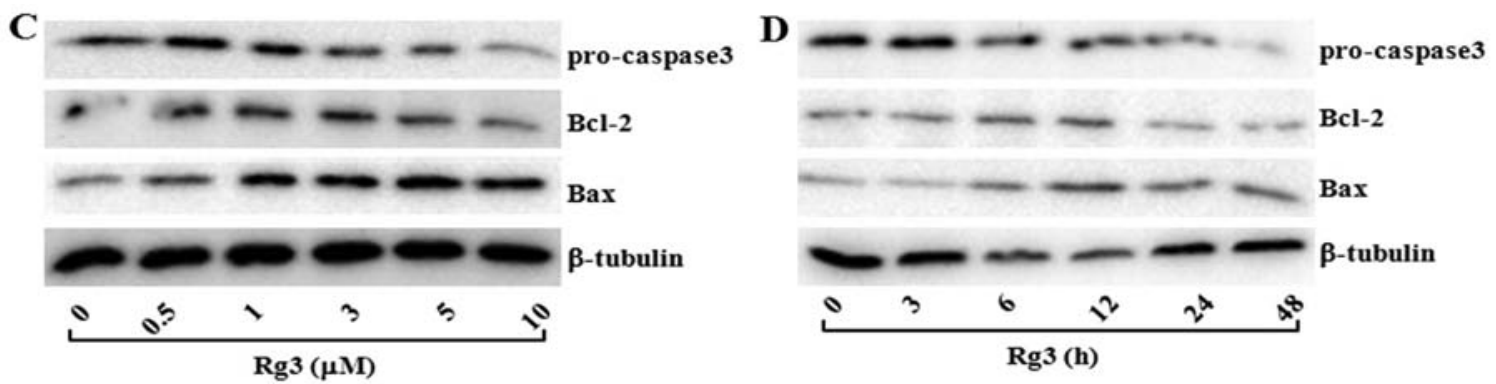

Figure 3. Rg3 induces apoptosis in U87MG cells. Cells were treated with $10 \mu \mathrm{M} \mathrm{Rg} 3$ for $24 \mathrm{~h}$ and were then examined by immunocytochemistry (A and B) and western blot analysis (C and D).

Under high-concentration treatment conditions, $\operatorname{Rg} 1$ and $\operatorname{Rg} 3$ showed markedly different patterns (Fig. 1A). We also treated U87MG cells with low concentrations of each of the two reagents. As shown in Fig. 1B-E, Rg3 clearly decreased the viability of cells in a dose- and time-dependent manner when compared to $\mathrm{Rg} 1$ treatment. These results provide evidence that $\mathrm{Rg} 3$ exerts an inhibitory effect against U87MG cells.

Rg3 induces apoptosis in U87MG cells. We used a variety of methods to clarify the findings of the observed $\mathrm{Rg} 3$ effects on cell viability and morphology. Cells that were treated with $\mathrm{Rg} 3$ exhibited cellular adhesion loss and morphological change undergoing rounding and shrinkage (Fig. 2A). In addition, flow cytometry was performed to reaffirm the inhibitory effects of $\mathrm{Rg} 3$ on the cells, and $\mathrm{Rg} 3$-treated cells showed apoptosis, with a peak from 2.9 to 54.6 (Fig. 2B). To identify the type of cell death, U87MG cells were treated with $\mathrm{Rg} 3$ and then stained by TUNEL assay (Fig. 2C). The numbers of positively stained cells (green) were visibly increased after treatment with $\mathrm{Rg} 3$ when compared to the untreated condition. These findings suggest that RG3 induced apoptotic changes in the cells. Moreover, the cells treated with $\mathrm{Rg} 3$ were stained by immu- nocytochemistry using a pro-apoptotic member, Bax, and an anti-apoptotic member, Bcl-2 (16) (Fig. 3A and B). The level of Bax expression was high, whereas Bcl-2 expression was very low. Similarly, western blot analysis indicated that the levels of pro-caspase 3 and Bcl-2 expression were universally decreased in cells that were treated with different concentrations of $\mathrm{Rg} 3$ for various lengths of time, but the level of Bax expression increased in a dose- (Fig. 3C) and time- (Fig. 3D) dependent manner. These results indicate that $\mathrm{Rg} 3$ induced apoptosis in U87MG cells.

Effect of Z-VAD-fmk on U87MG cells during Rg3-induced apoptosis. To verify the involvement of the caspase cascade in Rg3-induced apoptosis, the cells were pre-exposed to the general caspase inhibitor, Z-VAD-fmk. Caspases, the interleukin-1 $\beta$-converting enzyme family proteases, are one of the major executors of the apoptotic process, and they convey the apoptotic signal via induction of death receptors $(17,18)$. Caspases have been reported as a class of cysteine proteases including several representatives involved in apoptosis (19). However, the results of our present study indicate that the cell viability of the group that was pre-treated with the caspase 

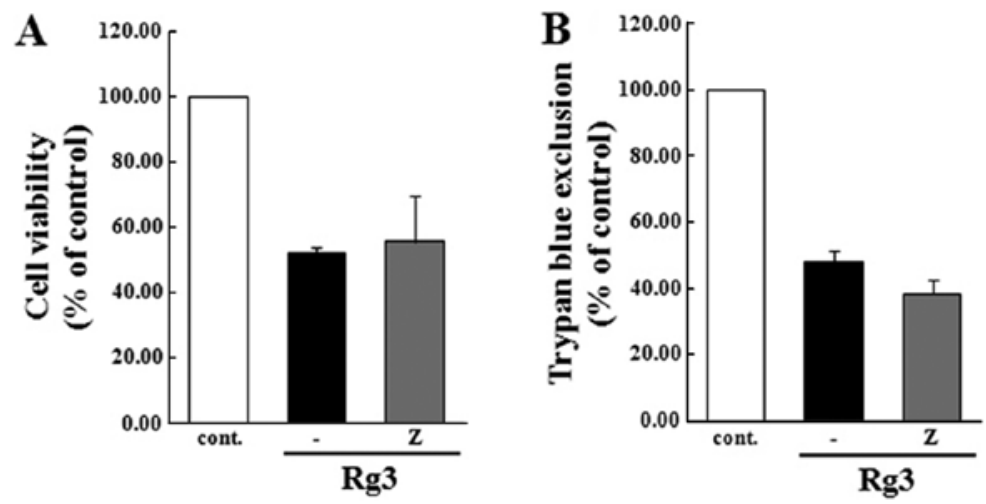

Figure 4. Rg3-induced apoptosis is not directly correlated with caspase cascade. Cells were pre-treated with $20 \mu \mathrm{M} \mathrm{Z-VAD-fmk} \mathrm{for} 1 \mathrm{~h}$, after which they were treated with $10 \mu \mathrm{M} \mathrm{Rg} 3$ for $24 \mathrm{~h}$ and analyzed by MTT assay (A) and trypan blue exclusion (B). The data are the means \pm SEM of four independent experiments. ${ }^{*} \mathrm{P}<0.05$ when compared to the control without Rg3. The scale bar indicates $400 \mu \mathrm{m}$.
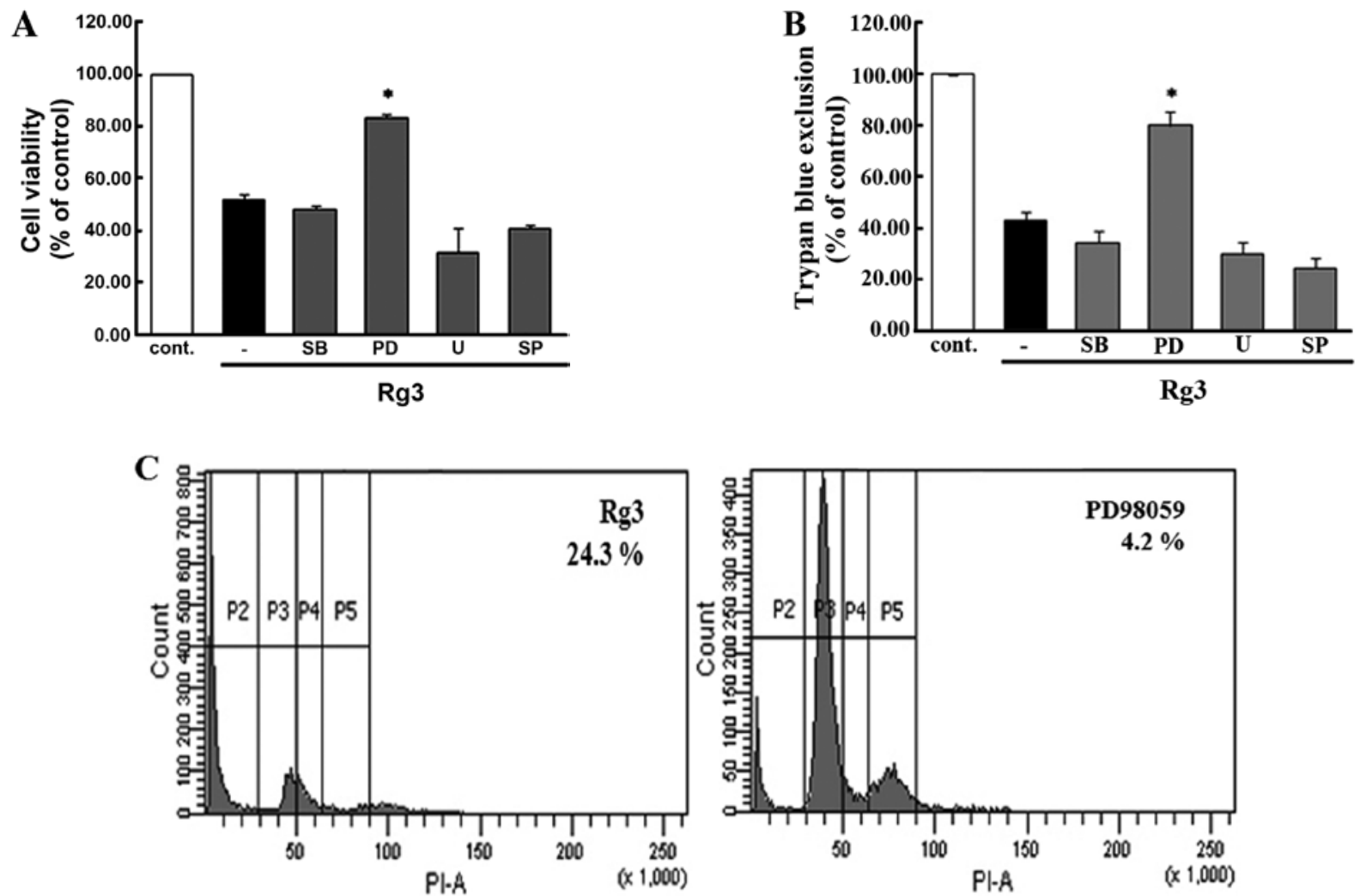

Figure 5. Rg3-induced apoptosis is related to MEK signaling. Cells were pre-treated with $25 \mu \mathrm{M}$ SP600125 (SP), $20 \mu \mathrm{M}$ SB203580 (SB), $20 \mu \mathrm{M}$ PD98059 (PD) and $20 \mu \mathrm{M} \mathrm{U} 0126$ (U), and then treated with $10 \mu \mathrm{M} \mathrm{Rg} 3$ for $24 \mathrm{~h}$. The U87MG cells were measured using an MTT assay (A) and trypan blue exclusion (B) and were examined by flow cytometric analysis $(C)$. The data reported are the means \pm SEM of four independent experiments. ${ }^{*} \mathrm{P}<0.05$ when compared to the control without $\operatorname{Rg} 3$.

cascade inhibitor was sustained in the Rg3-treated group (Fig. 4), suggesting that the caspase cascade does not regulate $\mathrm{Rg} 3$-induced apoptosis in U87MG cells.

Effect of mitogen-activated protein kinases (MAPKs) on U87MG cells during Rg3-induced apoptosis. MAPK signaling cascades are composed of a large group of serine/ threonine kinases. The MAPKs mediate signal transduction from the cell surface to the nucleus and are actively involved in converting a wide variety of extracellular stimuli commonly expressed in various cell types $(20,21)$. Several studies have shown that the MAPK signaling pathway plays an important role in the regulation of cellular growth, survival, apoptosis and differentiation (22-24). Moreover, it has been established that MAPK consists of three parallel kinase modules, ERK, JNK and p-38-MAPK. Overall, MEK, a key kinase, is responsible for the upstream signals from Ras and Raf via activation of ERK (25). Based on these findings, we examined the effects of $\operatorname{Rg} 3$ on the viability of U87MG cells by conducting a variety of methods. Cells pre-treated with inhibitors of MAPK family members were measured by MTT assay (Fig. 5A) and trypan exclusion assay (Fig. 5B). To confirm these results, we 

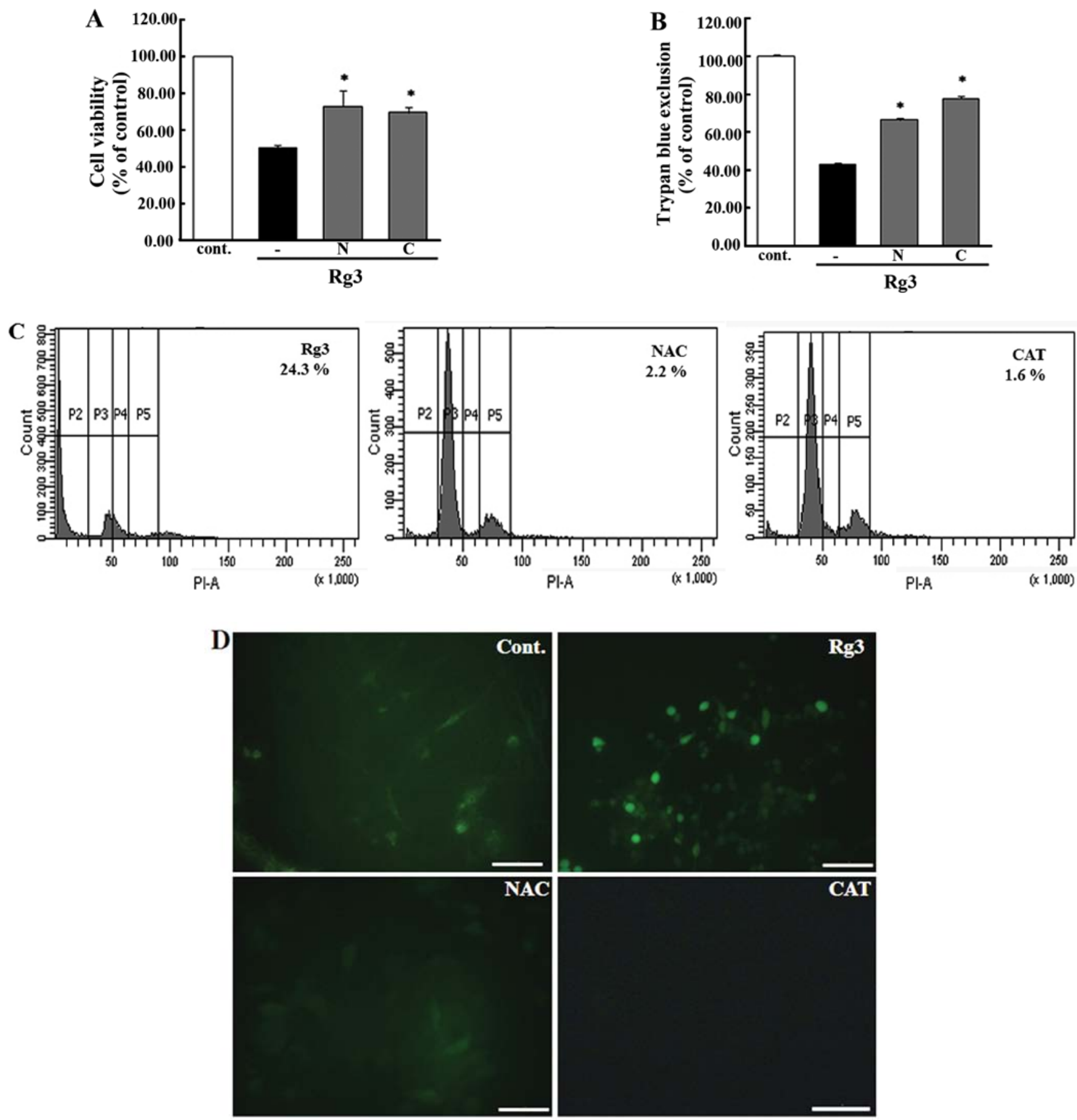

Figure 6. Rg3-induced apoptosis is specifically related to the antioxidant enzyme system. Cells were pre-treated with $10 \mu \mathrm{M} \mathrm{NAC} \mathrm{(N)} \mathrm{and} 800 \mathrm{U} / \mathrm{ml} \mathrm{CAT}(\mathrm{C})$, after which they were treated with $10 \mu \mathrm{M} \mathrm{Rg} 3$ for $24 \mathrm{~h}$. The U87MG cells were measured using an MTT assay (A) and trypan blue exclusion (B) examined by flow cytometry (C) and the DCF fluorescence intensity was assessed by fluorescence microscopy (D). The data reported are the means \pm SEM of four independent experiments. ${ }^{*} \mathrm{P}<0.05$ when compared to the control without Rg3.

conducted flow cytometry (Fig. 5C) to compare the inhibitor treatment group to the untreated control group. Our data clearly show that Rg3-induced apoptosis in U87MG cells through PD98059 (specific inhibitor of MEK1/2).

Effect of antioxidant enzyme system on U87MG cells during Rg3-induced apoptosis. Antioxidant enzymes are endogenous proteins that are well known for their involvement in protecting cells from ROS damage (26). ROS are extremely toxic to organisms $(27,28)$ and oxidative stress can lead to damage to cellular structures and is related to a number of diseases, including cancer (29). The present study was conducted to verify whether ROS is associated with the regulation of $\mathrm{Rg} 3$-induced cellular apoptosis. To accomplish this, we used antioxidant enzyme inhibitor for the treatment of cells. As shown in Fig. 6A and B, in the group pre-treated with antioxidant enzymes such as $\mathrm{N}$-acetylcysteine (NAC) and catalase (CAT), all cells were sustained as in the control group, except for those that received the $\operatorname{Rg} 3$ treatment, which showed decreased cell viability. To confirm these results, we 
conducted flow cytometry (Fig. 6C) to compare the group that received the antioxidant pre-treatment to the untreated control group. Moreover, we measured the fluorescence activation of ROS using DCFH-DA staining (Fig. 6D) as DCFH-DA is generally used for detection of ROS formation (30). DCFH-DA expression was not detected in cells that were pre-treated with CAT and NAC, while the Rg3-treated group showed increased DCFH-DA expression when compared to the control. Taken together, these findings indicate that ROS is involved in $\mathrm{Rg} 3$-induced apoptosis, particularly through the work of antioxidant enzymes system.

\section{Discussion}

Studies of the chemo-preventive effect of anticancer reagents have recently begun to focus on naturally-occurring chemical compounds in plants and animals. KRG is well-recognized in traditional Korean medicine as having a pharmacological effect (6-8). Among various components of KRG, ginsenosides are the most widely known. These compounds have diverse, beneficial biochemical activities, including chemo-preventive effects against diseases. $\operatorname{Rg} 3$ has negative effects on cancer growth, such as inhibition of metastasis and angiogenesis (31), confirming its usefulness as a novel anticancer agent (32). Rg3 is also an effective chemical reagent of a saponin, a unique component of KRG that can be extracted from ginseng $(12,33)$. It has been reported that $\mathrm{Rg} 3$ has potential cancer-preventive effects owing to its suppression of invasion, metastasis and growth of various forms of cancer and neovascularization $(32,34)$. Moreover, $\operatorname{Rg} 3$ has been reported to induce the reduction of metastasis and the amount of tumor development in colon and ovarian cancer (35), as well as to inhibit angiogenesis in prostate (15) and lung cancer (36).

Effective and less-invasive alternatives for cancer treatment are actively being developed. To date, surgical techniques and chemotherapies such as reagents targeting specific molecules have been applied to improve the prognosis of cancer treatment.

Despite several novel trials for its treatment, GBM is one of the most aggressive and invasive malignant tumor forms of human cancer $(1,2)$. As standard treatment methods for cancer such as chemotherapy, microsurgical techniques and radiotherapy have been shown to be ineffective at ameliorating GBM, the prognosis of GBM remains poor $(5,37,38)$. Consequently, recent studies have focused on the development of new treatment modalities for cancer such as biological therapy and chemotherapy using novel substances that can be extracted from a variety of foods.

This study was conducted to investigate the effects of Rg3 on U87MG cells. Furthermore, we attempted to identify the molecular mechanisms of cell death induced by $\mathrm{Rg} 3$ using various inhibitory agents.

U87MG cells were used to explore the effects and regulatory mechanisms of $\mathrm{Rg} 3$ on the human glioblastoma cell line. First, we treated cells with $\operatorname{Rg} 3$ (panaxadiol group) and Rg1 (panaxatriol group). The results of these experiments revealed different effects on the cells, particularly under high concentration conditions (9). Specifically, the inhibition of U87MG cell growth was much greater when cells were treated with $\operatorname{Rg} 3$ than with $\operatorname{Rg} 1$, and these differences occurred in a dose- dependent manner (Fig. 1A). We also found that Rg1 had no inhibitory effect on cell proliferation or viability, while $\operatorname{Rg} 3$ did (Fig. 1B-E).

Some studies have reported that $\mathrm{Rg} 1$ promotes angiogenesis in vivo and in vitro by inducing vascular endothelial growth factor (VEGF), a mediator of angiogenesis (9). These results suggest that Rg1 may be the main candidate for angiotherapy due to its potential to induce wound healing and tissue regeneration.

We verified whether the inhibitory effect of $\operatorname{Rg} 3$ was related to cell apoptosis. Observation of morphological changes in the cells, flow cytometry, TUNEL assay and expression of Bax or Bcl-2 indicated that Rg3 led to apoptosis (Figs. 2 and 3).

Apoptosis or programmed cell death is a common type of cell death, and is one of the principal mechanisms involved in tissue homeostasis (39-41). This physiological 'cell suicide' program is essential for diverse cellular processes, particularly for the elimination of damaged, infected and redundant cells. Apoptosis is induced by a disparate variety of pathways that can be further divided into intrinsic and extrinsic apoptotic pathways. The general methods for effectively detecting apoptotic cells are the TUNEL assay and flow cytometry $(42,43)$.

We conducted a TUNEL assay using an in situ Cell Death Detection kit. As expected, positive-stained cells (green) were highly detected by DNA fragmentation labeling of the terminal end of nucleic acids. Cells treated with $\mathrm{Rg} 3$ showed morphological changes ranging from rounding shape to shrinkage. Furthermore, the level of Bax expression was largely detected in the cells, but that of Bcl-2 was not. Collectively, these results indicate that Rg3 induced the death of U87MG cells through apoptosis.

The relationship between GBM and $\operatorname{Rg} 3$ was uncertain, therefore we investigated whether $\operatorname{Rg} 3$ conducted molecular mechanisms during apoptosis of the cells.

$\mathrm{Rg} 3$ was previously reported to exert anticancer activity through various molecular pathways including Wnt/ $\beta$-catenin signaling (44), the caspase-dependent signaling cascade (45) and the mitochondrial pathway (46) in different cell lines. Therefore, we examined the involvement of the caspase cascade in the effects of $\mathrm{Rg} 3$ treatment. The intracellular cysteine enzymes mediating the caspase cascade are well defined as a family of proteins that are major executors of apoptosis processes $(17,18)$. Although the caspase cascade has been shown to activate apoptosis, the roles of the individual caspases remain uncertain. The results of the present study showed that the caspase cascade was not involved in the apoptosis signal induced by Rg3 (Fig. 4).

We demonstrated that MAPK signaling may be related to Rg3-induced anticancer activity. MAPK cascades are the main signaling pathways involved in various cellular responses including proliferation, survival, inflammation and differentiation $(21,47)$. The key factors involved in these cascades are MAPK/ERK, SAPK/JNK, and p38-MAPK. Moreover, the MAPK/ERK signaling cascade is well known to occur in response to Raf and MEK in cancer progression and cancer growth $(23,25,48)$. The MAPK ERK signaling cascade starts with the phosphorylation and activation of MEK by Raf, which is followed by the phosphorylation and activation of ERK by MEK $(22,49)$. MEK plays a specific dual role in phosphorylation of tyrosine and activation of threonine residues on ERKs 1 
and 2. However, the relationship between JNK and p38 MAPK and their involvement in cancer signaling pathways is less clearly established.

As shown in Fig. 5, pretreatment of PD98059 on the U87MG cells showed maintained cell viability markedly better than other inhibitor pretreatment groups compared with control. MEK signaling has relevance to $\mathrm{Rg} 3$-induced apoptosis, while other inhibitors of MAPKs had only a slight effect on the viability of U87MG cells. We indicated if the MEK signaling pathway could be controlled in living systems, cancer could be also controlled in the same system. The results of the present study suggest that efficient cancer treatment can inhibit the MEK signaling pathway.

ROS occur naturally in organisms as side-products from the homeostatic intracellular signaling and as a part of the defense mechanism of the immune system. Moreover, ROS have been found to directly injure cells and to play an important role in the physiological and pathological processes of diseases including ischemia, tissue damage, endocrine dysfunction and cancer $(26,50,51)$. To accelerate oxidative stress to exert cell damage, antioxidant systems and capacity must fail and decline. ROS are neutralized by antioxidant enzymes such as superoxide dismutase (SOD), glutation peroxidase (GSHPx), glutation reductase (GR) and CAT (52-54). Moreover, antioxidant enzyme imbalances induce the arrest of cell proliferation and growth, leading to cell cycle arrest being switched on by activated p53 proteins, resulting in apoptosis $(55,56)$.

We found that antioxidant enzyme systems have significant control over molecular signaling pathways and the mechanism of $\mathrm{Rg} 3$-induced apoptosis in U87MG cells. As shown in Fig. 6A-C, cells that were treated with $\mathrm{Rg} 3$ displayed decreased viability. However, the group subjected to antioxidant enzyme pretreatment showed sustained cell viability, similar to the results observed in the control group. CAT is a tetrameric heme containing an enzyme that degrades hydrogen peroxide into oxygen and water $(53,57)$. $\mathrm{N}$-acetylcysteine and $\mathrm{N}$-acetyl-L-cysteine (NAC) are thiols that act as mucolytic agents and are derived from sulfhydryl groups in cells and scavengers that interact with the ROS of free radicals $(58,59)$. These are the main parts of the enzymatic and protective system against ROS, and are known to be indispensable to ROS neutralization under oxidative stress conditions (56).

To confirm that the antioxidant enzyme system exerts an effect on the molecular mechanism during $\mathrm{Rg} 3$-induced apoptosis, we stained the cells with DCFH-DA (Fig. 6D). The results revealed that $\mathrm{Rg} 3$-induced apoptosis signaling was regulated by CAT, and that this association was triggered by the antioxidant enzyme system.

There have been few studies on Rg3 for the treatment of GBM, and there have been few investigations of its molecular mechanism in such treatments. The results of our present study indicated that $\mathrm{Rg} 3$ has a greater inhibitory effect on the U87MG human glioblastoma cell line, and that its apoptotic mechanism was regulated through MEK and ROS. We expect $\operatorname{Rg} 3$ to be the major candidate for natural treatment of GBM, as well as other types of cancer. Further studies using various cancer cells should be conducted to verify the anticancer effects of $\operatorname{Rg} 3$ and its molecular mechanism on these cells.

\section{Acknowledgements}

The present study was supported by the Medical Research Institute and Pusan Cancer Center Grant (2011-29), Pusan National University Hospital.

\section{References}

1. Chamberlain MC: Treatment options for glioblastoma. Neurosurg Focus 20: E19, 2006.

2. Chamberlain M: Evolving strategies: future treatment of glioblastoma. Expert Rev Neurother 11: 519-532, 2011.

3. Schratter-Sehn AU and Marosi C: Treatment of glioblastoma recurrences. Wien Med Wochenschr 161: 1-2, 2011 (In German).

4. Kala M, Srámek V, Houdek M, Vaverka M and Zmrzlík P: Treatment of glioblastoma multiforme. Cas Lek Cesk 132: 653-656, 1993 (In Czech).

5. Holland EC: Glioblastoma multiforme: the terminator. Proc Natl Acad Sci USA 97: 6242-6244, 2000.

6. Yun TK, Lee YS, Lee YH, Kim SI and Yun HY: Anticarcinogenic effect of Panax ginseng C.A. Meyer and identification of active compounds. J Korean Med Sci 16 (Suppl): S6-S18, 2001.

7. De Souza LR, Jenkins AL, Sievenpiper JL, Jovanovski E, Rahelić D and Vuksan V: Korean red ginseng (Panax ginseng C.A. Meyer) root fractions: differential effects on postprandial glycemia in healthy individuals. J Ethnopharmacol 137: 245-250, 2011.

8. Varjas T, Nowrasteh G, Budán F, et al: Chemopreventive effect of Panax ginseng. Phytother Res 23: 1399-1403, 2009.

9. Helms S: Cancer prevention and therapeutics: Panax ginseng. Altern Med Rev 9: 259-274, 2004.

10. Shin HR, Kim JY, Yun TK, Morgan G and Vainio H: The cancerpreventive potential of Panax ginseng: a review of human and experimental evidence. Cancer Causes Control 11: 565-576, 2000.

11. Attele AS, Wu JA and Yuan CS: Ginseng pharmacology: multiple constituents and multiple actions. Biochem Pharmacol 58: 1685-1693, 1999.

12. Yun TK: Experimental and epidemiological evidence on non-organ specific cancer preventive effect of Korean ginseng and identification of active compounds. Mutat Res 523-524: 63-74, 2003.

13. Lu P, Su W, Miao ZH, Niu HR, Liu J and Hua QL: Effect and mechanism of ginsenoside Rg3 on postoperative life span of patients with non-small cell lung cancer. Chin J Integr Med 14: 33-36, 2008.

14. Ji C, Ren F and Xu M: Caspase-8 and p38MAPK in DATS-induced apoptosis of human CNE2 cells. Braz J Med Biol Res 43: 821-827, 2010.

15. Kim HS, Lee EH, Ko SR, Choi KJ, Park JH and Im DS: Effects of ginsenosides $\mathrm{Rg} 3$ and $\mathrm{Rh} 2$ on the proliferation of prostate cancer cells. Arch Pharm Res 27: 429-435, 2004.

16. Youle RJ and Strasser A: The BCL-2 protein family: opposing activities that mediate cell death. Nat Rev Mol Cell Biol 9: 47-59, 2008.

17. Fan TJ, Han LH, Cong RS and Liang J: Caspase family proteases and apoptosis. Acta Biochim Biophys Sin (Shanghai) 37: 719-727, 2005.

18. Olsson M and Zhivotovsky B: Caspases and cancer. Cell Death Differ 18: 1441-1449, 2011.

19. Cohen GM: Caspases: the executioners of apoptosis. Biochem $\mathbf{J}$ 326: 1-16, 1997.

20. Raman M, Chen W and Cobb MH: Differential regulation and properties of MAPKs. Oncogene 26: 3100-3112, 2007.

21. Seger R and Krebs EG: The MAPK signaling cascade. FASEB J 9: 726-735, 1995

22. Roux PP and Blenis J: ERK and p38 MAPK-activated protein kinases: a family of protein kinases with diverse biological functions. Microbiol Mol Biol Rev 68: 320-344, 2004.

23. Zohrabian VM, Forzani B, Chau Z, Murali R and Jhanwar-Uniyal M: Rho/ROCK and MAPK signaling pathways are involved in glioblastoma cell migration and proliferation. Anticancer Res 29: 119-123, 2009.

24. Fang JY and Richardson BC: The MAPK signalling pathways and colorectal cancer. Lancet Oncol 6: 322-327, 2005.

25. Kolch W: Meaningful relationships: the regulation of the Ras/Raf/MEK/ERK pathway by protein interactions. Biochem J 351: 289-305, 2000. 
26. Circu ML and Aw TY: Reactive oxygen species, cellular redox systems, and apoptosis. Free Radic Biol Med 48: 749-762, 2010.

27. Stadtman ER: Protein oxidation and aging. Science 257: 1220-1224, 1992.

28. Stadtman ER: Role of oxidant species in aging. Curr Med Chem 11: 1105-1112, 2004

29. Kannan K and Jain SK: Oxidative stress and apoptosis. Pathophysiology 7: 153-163, 2000.

30. Gomes A, Fernandes E and Lima JL: Fluorescence probes used for detection of reactive oxygen species. J Biochem Biophys Methods 65: 45-80, 2005

31. Yue PY, Wong DY, Wu PK, et al: The angiosuppressive effects of 20(R)- ginsenoside Rg3. Biochem Pharmacol 72: 437-445, 2006.

32. Keum YS, Han SS, Chun KS, et al: Inhibitory effects of the ginsenoside $\mathrm{Rg}_{3}$ on phorbol ester-induced cyclooxygenase-2 expression, NF- $\mathrm{kB}$ activation and tumor promotion. Mutat Res 523-524: 75-85, 2003.

33. Lee JI, Ha YW, Choi TW, et al: Cellular uptake of ginsenosides in Korean white ginseng and red ginseng and their apoptotic activities in human breast cancer cells. Planta Med 77: 133-140, 2011.

34. Christensen LP: Ginsenosides chemistry, biosynthesis, analysis, and potential health effects. Adv Food Nutr Res 55: 1-99, 2009.

35. Xu TM, Cui MH, Xin Y, et al: Inhibitory effect of ginsenoside Rg3 on ovarian cancer metastasis. Chin Med J (Engl) 121: 1394-1397, 2008.

36. Liu TG, Huang Y, Cui DD, et al: Inhibitory effect of ginsenoside $\mathrm{Rg} 3$ combined with gemcitabine on angiogenesis and growth of lung cancer in mice. BMC Cancer 9: 250, 2009.

37. Henson JW: Treatment of glioblastoma multiforme: a new standard. Arch Neurol 63: 337-341, 2006.

38. Wong ET and Yamaguchi NH: Treatment advances for glioblastoma. Expert Rev Neurother 11: 1343-1345, 2011.

39. Yue TL, Ohlstein EH and Ruffolo RR Jr: Apoptosis: a potential target for discovering novel therapies for cardiovascular diseases. Curr Opin Chem Biol 3: 474-480, 1999.

40. Hickman JA: Apoptosis induced by anticancer drugs. Cancer Metastasis Rev 11: 121-139, 1992.

41. Kerr JF, Wyllie AH and Currie AR: Apoptosis: a basic biological phenomenon with wide-ranging implications in tissue kinetics. Br J Cancer 26: 239-257, 1972.

42. Nagata S: DNA degradation in development and programmed cell death. Annu Rev Immunol 23: 853-875, 2005.

43. Wieder R: TUNEL assay as a measure of chemotherapy-induced apoptosis. Methods Mol Med 111: 43-54, 2005.
44. He BC, Gao JL, Luo X, et al: Ginsenoside Rg3 inhibits colorectal tumor growth through the down-regulation of $\mathrm{Wnt} / \beta$-catenin signaling. Int J Oncol 38: 437-445, 2011.

45. Jiang JW, Chen XM, Chen XH and Zheng SS: Ginsenoside Rg3 inhibit hepatocellular carcinoma growth via intrinsic apoptotic pathway. World J Gastroenterol 17: 3605-3613, 2011.

46. Yuan HD, Quan HY, Zhang Y, Kim SH and Chung SH: 20(S)-Ginsenoside Rg3-induced apoptosis in HT-29 colon cancer cells is associated with AMPK signaling pathway. Mol Med Rep 3: 825-831, 2010.

47. Dhanasekaran DN and Johnson GL: MAPKs: function, regulation, role in cancer and therapeutic targeting. Oncogene 26 : 3097-3099, 2007.

48. Kyriakis JM, App H, Zhang XF, et al: Raf-1 activates MAP kinase-kinase. Nature 358: 417-421, 1992.

49. Mavria G, Vercoulen Y, Yeo M, et al: ERK-MAPK signaling opposes Rho-kinase to promote endothelial cell survival and sprouting during angiogenesis. Cancer Cell 9: 33-44, 2006.

50. Allen CL and Bayraktutan U: Oxidative stress and its role in the pathogenesis of ischaemic stroke. Int J Stroke 4: 461-470, 2009

51. Wiseman H and Halliwell B: Damage to DNA by reactive oxygen and nitrogen species: role in inflammatory disease and progression to cancer. Biochem J 313: 17-29, 1996.

52. Bannister JV, Bannister WH and Rotilio G: Aspects of the structure, function, and applications of superoxide dismutase. CRC Crit Rev Biochem 22: 111-180, 1987.

53. Chelikani P, Fita I and Loewen PC: Diversity of structures and properties among catalases. Cell Mol Life Sci 61: 192-208, 2004

54. Rhee SG, Chae HZ and Kim K: Peroxiredoxins: a historical overview and speculative preview of novel mechanisms and emerging concepts in cell signaling. Free Radic Biol Med 38: 1543-1552, 2005.

55. Oberley TD and Oberley LW: Antioxidant enzyme levels in cancer. Histol Histopathol 12: 525-535, 1997.

56. Kong Q and Lillehei KO: Antioxidant inhibitors for cancer therapy. Med Hypotheses 51: 405-409, 1998.

57. Bechtel W and Bauer G: Catalase protects tumor cells from apoptosis induction by intercellular ROS signaling. Anticancer Res 29: 4541-4557, 2009.

58. Zafarullah M, Li WQ, Sylvester J and Ahmad M: Molecular mechanisms of N-acetylcysteine actions. Cell Mol Life Sci 60: 6-20, 2003

59. Aruoma OI, Halliwell B, Hoey BM and Butler J: The antioxidant action of $\mathrm{N}$-acetylcysteine: its reaction with hydrogen peroxide, hydroxyl radical, superoxide, and hypochlorous acid. Free Radic Biol Med 6: 593-597, 1989. 